\title{
Enhancing Leaders' Emotional Intelligence: Why Mindfulness?
}

\author{
Tarek M. Kaoun, ME.d., CTP \\ Learning and Development Professional
}

\begin{abstract}
As an adult-learning practitioner, I am intrigued by the process of helping learners, especially leaders, develop through the affective domain. Although leaders in my experience often comprehend the lexicon of emotional intelligence (EI), incorporating EI for leadership development has proven elusive. While research suggests EI is difficult to develop in people, this paper argues that leaders can do so by tapping into a higher mental and emotional state, and that such mindfulness practices can enhance leaders' EI. Findings suggest that (a) EI positively impacts leadership effectiveness, (b) mindfulness can serve as a method for growing EI, and (c) mindfulness can enhance the practice of leadership. The paper offers recommendations for adultlearning practitioners who create EI- and mindfulness-based training and provides directions for future research.
\end{abstract}

\section{Introduction}

As an adult-learning practitioner with 10 years of experience, I take great satisfaction in developing my learners, especially leaders; that is to enhance my learners' abilities within the cognitive, psychomotor, and affective domains of learning (Clarke, 2015). What has become apparent to me is not only how the affective domain underpins so many of our (in)actions but also how difficult it can be to develop in learners. Given that the affective domain relates to developing our emotional state, attitudes, and mental capabilities (Clarke, 2015), I have incorporated emotional intelligence (EI) extensively in my teaching practices, especially when teaching leaders. In my experience, however, I noticed that EI has become a buzz term that many use yet face challenges in its implementation. Furthermore, there is evidence that suggests it can be rather difficult to grow one's EI (Chamorro-Premuzic, 2013). I also have discovered through my experience that we must tap into learners' deepest mental and emotional capabilities in order to cultivate their EI; I believe this is necessary as I have found that understanding EI on a conceptual level appears not to contribute to EI development in learners. Given this realization, I have taken a keen interest in the practice of mindfulness and have long theorized that it can unlock the full potential of learners' EI. As such, this paper's goal is to demonstrate why mindfulness practices should be used to enhance leaders' EI. I begin by describing the importance of the affective domain for our learning, along with EI's impact on leadership. I then make connections between EI and mindfulness, discuss why mindfulness should be used to cultivate EI, and explain the relationship between mindfulness and leadership. I conclude the paper with recommendations for adult-learning practitioners who create EI- and mindfulnessbased training, followed by directions for future research. 


\section{Importance of Affective Domain and Impact of EI on Leadership}

Learning can be categorized in three distinct domains: cognitive, affective, and psychomotor (Clarke, 2015). The cognitive domain of learning, described in Bloom's (1956) taxonomy, corresponds to intellectual skills such as memorization of facts and defining key concepts. Krathwohl, Bloom, and Masia (1964) codified the affective domain, which specifically is concerned with the self, including feelings and emotions. Finally, the psychomotor domain (Simpson, 1972) primarily refers to the use of coordinated physical movement.

I create and deliver learning using all three of the above domains. Of the three, I find that the psychomotor and cognitive domains tend to be easier to quantify and assess; for example, asking learners to demonstrate a cognitive process can be as simple as having them explain what they understood, while psychomotor skills can be exhibited through mere role-play. As for the affective domain, however, it is rather difficult to assess and even explain how feelings, emotions, and the self can be developed, given that feelings and emotions are internal processes in the mind.

The importance of the affective domain can be traced back to the 1960s, at which time Piaget pointed out that "at no level, at no state, even in the adult, can we find behaviour or a state that is purely cognitive without emotion" (as cited in Frasson \& Heraz, 2012, p. 2). Furthermore, as Wight (1971) explained, "man's cognitive processes alone, no matter how well developed, can be of little service to him and to mankind unless he has learned to manage his feelings and to mobilize his total resources in the pursuit of meaningful, personal goals" (p. 15). More recent studies indicate that our decisions are largely made based on how we feel (Marchant, 2013); essentially, our feelings - which are grounded in emotions - guide the decisions we make (Marchant, 2013). I have often observed the complexities involved in my learners' decisionmaking process. For example, there are times that my learners have told me they understood the information they received but, given their feelings towards the information, decided not to implement the newly acquired knowledge into their day-to-day practices. Furthermore, there is evidence to suggest that the affective domain has been researched much less than and has received the least attention compared to the other domains of learning (Pierre \& Oughton, 2007). Still, there is a call for educators across sectors and in various disciplines to embrace the affective domain, as it is an essential aspect of human behaviour (Duczyminski, 2017; Yanofsky \& Nyquist, 2014).

In looking at the affective domain's effect on leadership, one can do so through the lens of EI given the latter's focus on emotions and feelings and the extent to which it has been researched since the 1990's. In terms of its impact, EI is "the single biggest predictor of performance in the workplace and the strongest driver of leadership and personal excellence" (Bradberry, 2014, para. 3). To build on this, leaders with high EI tend to be more effective in creating buy-in among their staff (Ferres \& Connell, 2004). In fact, leaders with very high EI were found to be so effective that they had no disengaged employees among their staff whatsoever (Palmer \& Gignac, 2012), and were also found to be more effective in communicating the goals of their organizations (Ugoani, Amu, \& Kalu, 2015). 
Theories of EI gained popularity in the 1990s, at which time Salovey and Mayer (1990) described it as "the ability to monitor one's own and others' feelings, to discriminate among them, and to use this information to guide one's thinking and action" (as cited in Velisavljevic, 2015, Definition section, para. 1). Essentially, this definition places emotions at the center of everything that we do. Salovey and Mayer (1997) later expanded their definition, noting that EI involves the ability to perceive accurately, appraise, and express emotion; the ability to access and/or generate feelings when they facilitate thought; the ability to understand emotion and emotional knowledge; and the ability to regulate emotions to promote emotional and intellectual growth. (As cited in Velisavljevic, 2015, Definition section, para. 5)

This expanded definition essentially links EI to our ability to perceive, express, and regulate ourselves and to empathize with others.

When considering EI, it is helpful to look at the work of Daniel Goleman (2004) who expanded upon Salovey and Mayer's earlier findings. Goleman (2004) added five key competencies that drive EI: self-awareness, self-regulation, motivation, empathy, and social skills (p. 88). Goleman describes self-awareness as "the ability to recognize and understand your moods, emotions, and drives, as well as their effect on others" (p. 88) - in other words, our ability to truly understand ourselves. Self-regulation is defined as "the ability to control or redirect disruptive impulses and moods" (Goleman 2004, p. 88), and how well we control our emotions and feelings is at the heart of self-regulation. Motivation is defined as "a passion to work for reasons that go beyond money or status" (Goleman, 2004, p. 88). With regards to motivation, Goleman (2004) also highlights the importance of persistence and resilience. Finally, Goleman (2004) defines empathy as "the ability to understand the emotional makeup of other people" (p. 88), and social skills as "proficiency in managing relationships and building networks. An ability to find common ground and build rapport" (p. 88).

When teaching leaders the competencies and skills needed to grow EI, I have made note of an interesting observation. Upon finishing their classes, the leaders were able to describe the importance of EI and cognitively grasp the various competencies and skills associated with EI. However, even though these leaders were fully engaged and focused in the classes, they had mentioned to me that that they were unable to demonstrate practical improvement in their emotional intelligence. Essentially, the leaders had explained to me that the training had no impact or effect on their behaviours whatsoever. As a learning and development professional, this challenge perplexed me. I decided to change my educational approach by leveraging a variety of exercises, but to no avail.

I thus began to realize that teaching EI merely from a cognitive perspective contributes very little to the creation or development of emotionally intelligent leaders. My belief is that EI is predicated on the need to push deeper into our mental and emotional capabilities in order to truly feel, experience, and understand EI. That is to say, we need to push beyond the surface. It is here that I have discovered and continue to explore the important connection between EI and mindfulness. 


\section{EI and Mindfulness}

I have witnessed many learners, including seasoned leaders, experience challenges growing their EI. As noted earlier, numerous studies have shown it can be difficult to develop EI (Chamorro-Premuzic, 2013; Kocis, 2017). Based on thousands of studies published since 1990, Tomas Chamorro-Premuzic (2013), a professor at University College London, claims that our capacity for EI "is firm, but not rigid" and that "our ability to identify and manage our own and others' emotions is ... influenced by our early childhood experiences and even genetics" (para. 4), which may explain why I have observed leaders' difficulty in developing their EI. Still, Chamorro-Premuzic (2013) adds that the firmness in our EI capacity "does not mean that we cannot change, but realistically, long-term improvements will require a great deal of dedication and guidance" (para. 4).

I have observed that individuals' inability to break down their preconceived notions and assumptions is one of the most significant obstacles preventing the growth of their EI. Said another way, if individuals assume they already are self-aware (even if they are not), they will see no reason to develop their self-awareness. In short, if an individual assumes that something is not possible, then it is not possible. I believe that assumptions can become limitations, distracting us from truly understanding ourselves and realizing our full potential. I believe the implications of assumptions are significant insofar as they can influence our thinking, which in turn influences our actions. Mindfulness may help break this cycle and allow us to tap into our deepest thoughts and become more self-aware. Because I have found many connections between EI and mindfulness - which I will explain below - I believe that mindfulness is an important aspect of growing EI.

The concept of mindfulness is rooted "in the ancient wisdom tradition of Buddhism" (Frizzell, Hoon, \& Banner, 2016, p. 21) but can also be linked to Hinduism and other spiritualbased traditions and religions (Selva, 2017). Although mindfulness practices began thousands of years ago, present-day mindfulness therapies are credited to Dr. Jon Kabat-Zinn, an American professor of medicine at the University of Massachusetts who developed a stress-reduction program in the late 1970s (Fossas, 2015). While theories of mindfulness have evolved over the years, the objective of mindfulness remains the same: to achieve a state of profound insight (Fossas, 2015). Rynes et al. (2007) define mindfulness as "enhanced attention to and a receptive awareness of current experiences" (as cited in Kroon, van Woerkom, \& Menting, 2017, p. 286). As Sethi (2009) explains, developing such heightened awareness "involves rigorous mental practice to develop focus, awareness and living in the moment" (as cited in Chesley \& Wylson, 2016, p. 319).

Broadening the definition and the scope of mindfulness, Dr. Kabat-Zinn also explains that the word for mind and heart in Asian languages are the same, and that mindfulness and compassion are interconnected (as cited in Szalavitz, 2012). This interconnectedness demonstrates that mindfulness contains an emotional component. When considering Salovey and Mayer's (1997) definition of EI noted earlier - that is, being able to "perceive accurately, appraise, and express emotion...access and/or generate feelings when they facilitate thought...understand emotion and emotional knowledge... [and] regulate emotions to promote emotional and intellectual growth" (as cited in Velisavljevic, 2015, Definition section, para. 5), 
connections between EI and mindfulness become clear. First, mindfulness enables heightened awareness (Sethi, 2009), and EI emphasizes the importance of perception (Salovey \& Mayer, 1997); essentially, it can be rather difficult to understand the various interpretations of perception without heightened awareness. Second, mindfulness corresponds to living in the moment (Sethi, 2009), while EI emphasizes the need to accurately understand emotions (Salovey \& Mayer, 1997); given that emotions occur in the moment, assessing them accurately as they occur is an important aspect of mindfulness. Third, the pursuit of emotional and intellectual growth is at the centre of EI (Salovey \& Mayer, 1997), while mindfulness emphasizes the importance of rigorous mental practice (Kroon et al., 2017). Said another way, how can emotional and intellectual growth come about without rigorous mental practice?

When drawing connections between EI and mindfulness, it also is helpful to consider how Goleman's (2004) five components of EI-motivation, self-awareness, self-regulation, empathy, and social skills - can be developed through mindfulness. For example, Brown and Ryan (2003) and Levesque and Brown (2007) found that individuals who are mindful are more intrinsically motivated (as cited in Kroon et al., 2017). Brown and Ryan (2003) also point out that those who are mindful have greater self-awareness and are better able to regulate their behaviour (as cited in Kroon et al., 2017). Good et al. (2016) in turn determined that mindfulness leads to greater self-control, which is essential for self-regulation (as cited in Chesley \& Wylson, 2016), while Baron (2016) found that individuals who practice mindfulness tend to be less judgmental, which corresponds to my observations in my professional practice as well. Finally, Frizzell et al. (2016) identified a positive correlation between individuals who practice mindful meditation and their ability to establish effective relationships - a key determinant of strong social skills.

Because preconceived assumptions (i.e., being judgemental) may limit our ability to become more emotionally intelligent, it appears that mindfulness is truly helpful here as well. Han and Zhang (2011) found that "employees who are not operating in a mindful state of awareness tend to act without thinking, may not notice when new information is available... [and] are not aware of or open to looking at alternate ways of accomplishing a certain task" (as cited in Chesley \& Wylson, 2016, p. 320). The individuals whom I have observed in my experience who make assumptions tend to relate with others in what I call "automatic mode"that is, they may not always reflect before acting and therefore rely on previously held beliefs to make decisions. This further reinforces that mindfulness can truly help with the breaking down of assumptions, which in turn may lead to heightened awareness - again a key component of EI. I will now examine connections between mindfulness and leadership.

\section{Relationship Between Mindfulness and Leadership}

While Leithwood et al. (1999) posit that "there is no agreed definition of the concept of leadership" (as cited in Bush \& Glover, 2003, p. 4), Gunter (2001) suggests that "leadership in educational settings is a crowded and busy terrain" (p. 94). Although there is a lack of consensus on the definition of leadership, I have chosen to focus on the transformational leadership theory as advanced by Burns (1978) - given that this theory is primarily focused on the "need for the organization to run smoothly and efficiently" (as cited in Shields, 2010, p. 563). As such, I define leadership as the practice of continual self-development with the intent of motivating and 
influencing others to achieve desirable results. The emphasis on results relates to personal growth for each individual being lead and also relates to achieving various organizational metrics. Given my definition of leadership, the purpose of this section is to examine the relationship between mindfulness and leadership. Frizzell et al. (2016) argue that "scholarship has not yet caught up with this emerging trend of leaders increasing use of mindfulness meditation and MBI [mindfulness based interventions]" (p. 15). As such, to contribute to the literature, I will examine the relationship between mindfulness and leadership using the following three themes: (a) leadership development, (b) leaders' ability to influence others, and (c) leaders' ability to achieve results through others.

Leadership Development. I have observed that leaders who are self-aware tend to clearly articulate their key areas of development and identify a unique action plan that will work for them. In discussing mindful leadership, Ehrlich (2015) associates mindfulness with "present, open, and engaged attention. When you pay active attention, you build self-awareness, which is the heart of leadership" (p. 22). Essentially, mindfulness can help leaders develop their selfawareness, which can play a central role in leadership development. Furthermore, developing self-awareness can be extremely important in helping transformational leaders understand how they fit into their organization's culture and create appropriate goals that are mutually beneficial for the organization they serve and themselves; this is especially important given that transformational leadership emphasizes the importance of culture development in an organization (Shields, 2010).

Frizzel et al., (2016) suggest that leaders who practice mindfulness end up with a more balanced leadership style, develop greater self-regulation, and improve their self-awareness. Moreover, leaders who practice mindfulness are also able to enhance their resiliency in their leadership roles (Chesley \& Wylson, 2016). In transformational leadership, I find that resiliency is a skill that is essential from a learning perspective, given that transformational leadership emphasizes the importance of leader's ability to manage organizational change (Shields, 2010); this is particularly important given that change requires leaders to constantly adapt.Ehrlich (2015) found that leaders who practice mindfulness become clear on their values, avoid reacting to emotions, and take better care of their bodies and self. Still, such findings raise some important questions: If leaders do not understand their values, how can they truly and authentically be persuaded to develop themselves? If leaders consistently react based on emotions, how will they practice patience and empathy? Finally, if leaders do not take care of themselves, how can they can achieve a healthy, optimum state of body and/or mind in order to learn and develop?

Influencing Others and Achieving Results. I have adopted the concept of transformational leadership, as advanced by Burns (1978) in my professional practice (as cited in Shields, 2010). One of the goals of transformational leadership is effective organizational change and growth (Shields, 2010). Transformational leaders play a critical role in helping the organization grow at a macro level, primarily by exercising their power to inspire others (Shields, 2010). Inspiration can positively influence teams and I have found that truly inspired teams achieve remarkable long-term and sustained results. Kroon et al. (2017) agree with this finding, noting that "transformational leaders spark the intrinsic motivation of employees, thereby stimulating their extra-role performance" (p. 284). Transformational leaders thus are able 
to influence their teams to the extent that they take on work beyond the expectations of their mandated accountabilities. But Kroon et al. (2017) also found that not all employees are "lucky enough" to have transformational leaders, and therefore they examined mindfulness as a substitute for transformational leadership because it "partly compensates for low levels of transformational leadership in fostering intrinsic motivation and in turn extra-role performance" (p. 284). Given this finding, mindfulness can be used as a complementary approach to if not a substitute for transformational leadership.

One of the most common challenges to achieving organizational results that I often hear from leaders is the latter's difficulty in keeping employees engaged in fast-changing environments and contexts. As Chesley and Wylson (2016) summarize, "today's business environment requires transformational organization change at an increased rate due to globalization, fast-paced technological change, and repeated instances of economic turbulence" (p. 317), and therefore leaders who adopt mindfulness in their professional roles "deal with ambiguity in new and different ways" (p. 318). Gebauer (2013) extends this line of thinking by highlighting the key concept of mindful organizing proposed by Weick and Sutcliffe (2001). Rooted in mindfulness, mindful organizing "provides the guiding principles and managerial mind-set to become more proactive and build collective organizational capabilities that anticipate the evolution of unexpected events and promote resilience in times of crisis" (Gebauer 2013, p. 205). I believe that leaders who are able to adapt to change(s) not only achieve greater business results but also remain engaged themselves and thereby contribute positively to staff engagement. As Gebauer (2013) explains, mindfulness organizing does not create reliability by control mechanisms, checklists or procedures in an attempt to assure stability. On the contrary, as uncertainty is considered the only certainty, preparedness for change and the ability to adapt quickly to new situations are the most important prerequisites for reliable performance. (pp. 207-208).

Therefore, mindfulness can be an essential aspect of helping leaders achieve results even in the fast-paced and unpredictable environments that Chesley and Wylson (2016) argue are becoming the norm.

The overall relationship between mindfulness and leadership can be best summed up by Joshua Ehrlich's Mindful-Leadership Model (see Figure 1). As Ehrlich (2015) explains, “the core of the model is connecting with yourself-with your spirit [i.e., purpose and values], emotion, mind and body. Once you can show up completely with all these aspects of yourself, you can connect with others and build relationships" (p. 23). Ehrlich (2015) adds that "once you have connected, you can lead and inspire" (p. 23). The link between EI and Ehrlich's model becomes clear as he highlights the role of emotions, demonstrating that EI is connected to mindfulness and that mindfulness is connected to leadership. In sum, mindfulness complements and enhances the practice of leadership. 


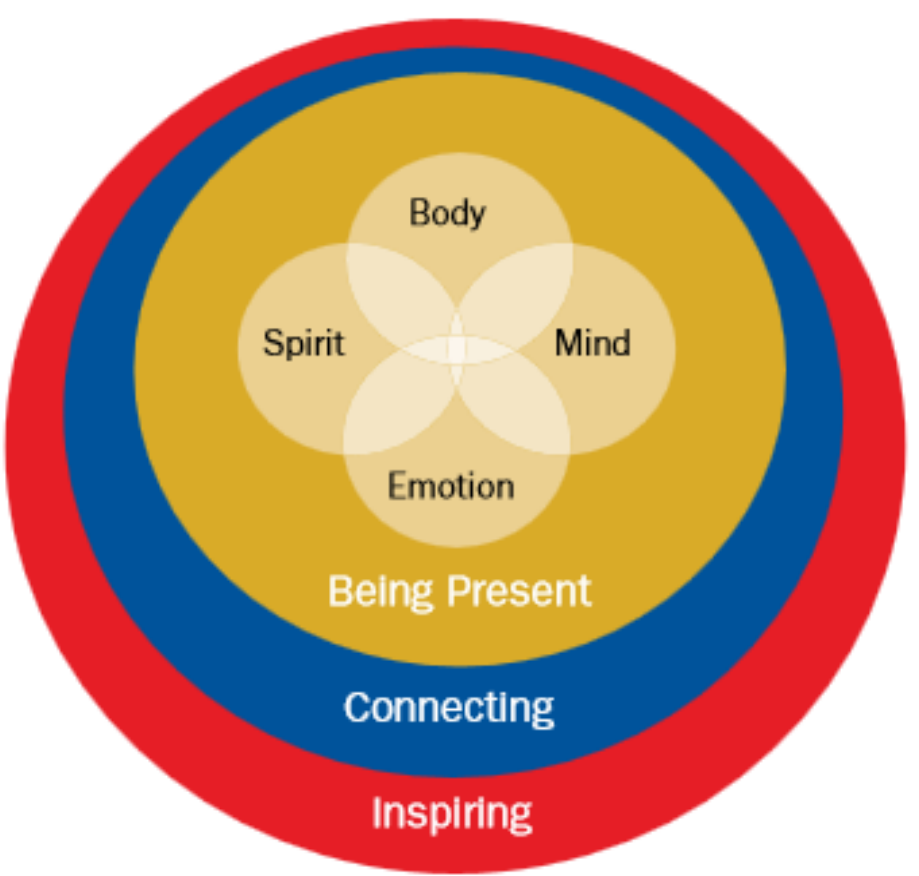

Figure 1. Ehrlich's (2015) mindful-leadership model.

\section{Recommendations for Adult-Learning Practitioners}

For the benefit of adult-learning practitioners who create and deliver emotional intelligence and mindfulness training, I offer a few recommendations in this section. The first recommendation is based on the 70-20-10 model for effective learning: 70\% of learning should happen on the job, 20\% through informal coaching and mentorship, and 10\% through formal, structured training courses and programs (Training Industry, 2014). Given that the 70-20-10 model suggests most learning happens on the job, adult-learning practitioners need to work with various leaders within their organization or institution to consider if the post-training environment is conducive for mindfulness practices. This is especially true for mindfulness because research suggests that many obstacles can arise post-training, which can hinder the implementation and adoption of mindfulness (Lyddy, Schachter, Reyer, \& Julliard, 2016). Some of these challenges include: loud noise and other distractions in the workplace, being too stressed with multiple task demands and not having enough time to complete such tasks, and social contexts in which some individuals feel they may not "fit" and are being stared at (Lyddy et al., 2016). Learning practitioners need to consider these obstacles and collaborate with various leaders to address them. For example, a designated room for mindful meditation might alleviate some individuals' feeling that others are staring at them. Similarly, such protected spaces for meditation may also lessen employees' sense of not having time or feeling burdened with too many tasks if work environments and schedules incorporated an allotted place and time for mindfulness.

My second recommendation is rooted in adult-learning principles as described by Knowles $(1980,1984)$ that inform adult learning (as cited in Pullagurla, 2014). One of these principles is that adults learn best through experiential exercises. Because mindfulness is rooted 
in practice, there likely will not be much value to learners if mindfulness is taught merely as a concept and not enough time is spent on practicing mindfulness. Therefore, learning practitioners need to ensure that mindfulness training incorporates sufficient time for practice. Furthermore, Vich (2015) explains that mindfulness interventions need to be voluntary, and I fully agree. Another principle of adult learning is that adults learn best when they take ownership of their learning and when they understand what is in it for them (Pullagurla, 2014). Learning practitioners can help learners take ownership of their learning by being very specific and clear on the benefits of mindfulness training. For an audience of leaders, for example, clarity on how mindfulness can enhance leadership is essential.

My third and final recommendation relates to the four stages of Kolb's (1974) experiential learning theory (as cited in McLeod, 2017). The first stage is concrete experience, referring to the stage when learners first experience the specific learning event. The second stage is reflective observation and relates to learners reflecting on what they experienced. The third stage is abstract conceptualization, during which time learners draw meaningful connections on their reflection. The fourth and final stage is active experimentation in which learners now put into practice everything that they have learned and experience the event again. As I described above, mindfulness needs to be experienced but it also can serve as a method for developing leaders' EI. Leveraging Kolb's experiential learning theory can serve as a framework to not only implement mindfulness into learners' practice but also enable them to make connections to EI.

To illustrate how this can occur, learning practitioners would first guide learners through mindfulness practices such as meditation. This concrete experience then would be followed by a reflective period during which time learners would be asked questions pertaining to EI, such as what the learners have learned about themselves and what they have noticed about their thoughts that they were not aware of previously. The learning practitioner then would guide learners through the abstract conceptualization stage by helping them make sense of their reflection. Such guidance could be implemented through strategic coaching whose goal would be to create a tangible action plan to be implemented in the active experimentation phase. Because this cycle may need to be repeated several times, the entire process would require a facilitator who is skilled not only in EI and mindfulness but also in the art of facilitation and coaching.

\section{Directions for Future Research}

Lyddy et al. (2016) claim there needs to be a greater understanding of how learners adopt mindfulness training in the workplace. Frizzell et al. (2016) in turn point out that although mindfulness meditation has been around for a long time, "what is new... is the scale at which it is available" (p. 21); in spite of the latter, Frizzell et al. also remind us that scholarship has not yet caught up with the adoption of mindfulness in leadership. Ehrlich (2015) thus challenges us to refocus in order to bring about a workplace that is conducive for mindfulness. Given these findings and my observations, mindfulness appears to be a ripe concept that has yet to be explored in depth. Furthermore, although I have reviewed many studies on EI, there is a dearth of research touching on how EI may be cultivated. This is one of the reasons that I have explored why mindfulness can be effective for developing EI. Further studies could examine the extent to which mindfulness may impact the growth of leaders' EI, perhaps utilizing Kolb's learning theory as a general framework and method. Each stage of Kolb's theory would need to be 
structured and prepared - with EI and mindfulness in mind - so that it could be repeated in a reliable and consistent manner. Such studies could also look at implications for the affective domain and determine the type of mindfulness practices that may be most beneficial.

\section{Conclusion}

The purpose of this paper was to raise awareness as to why mindfulness practices should be considered for growing leaders' EI. As such, I began this paper by exploring the importance of the affective domain for our learning along with the impact of EI on leadership. I then made connections between EI and mindfulness as well between mindfulness and leadership, which in turn provided a rationale as to why mindfulness may be a method through which EI can be developed in leaders. Finally, I provided recommendations for adult-learning practitioners to create EI and mindfulness training and provided directions for future research.

Findings suggest that EI positively impacts leader effectiveness. Furthermore, findings also indicate that mindfulness practice can serve as a method for growing EI and that mindfulness can enhance the practice of leadership. Such findings support my argument that we truly should consider mindfulness practices in our goal to enhance leaders' EI. Although mindfulness may appear to fall outside the sphere of conventional organizational and leadership theory, and to be difficult to leverage in our daily instructional practice, breaking through our old ways of thinking through mindfulness will help develop not only ourselves but also current and future leaders. 


\section{References}

Baron, L. (2016). Authentic leadership and mindfulness development through action learning. Journal of Managerial Psychology, 31(1), 296-311. doi:10.1108/JMP-04-2014-0135

Bloom, B. S. (Ed.). (1956). Taxonomy of educational objectives. Vol. 1: Cognitive domain. New York, NY: McKay.

Bradberry, T. (2014, January 9). Emotional intelligence-EQ. Forbes. Retrieved from https://www.forbes.com/sites/travisbradberry/2014/01/09/emotionalintelligence/\#68d2339b1ac0

Bush, T., \& Glover, D. (2003). School leadership: Concepts and evidence. Nottingham, UK: National College for School Leadership. Retrieved from http://dera.ioe.ac.uk/5119/14/dok217-engSchool_Leadership_Concepts_and_Evidence_Redacted.pdf

Chamorro-Premuzic, T. (2013 May 29). Can you really improve your emotional intelligence? Harvard Business Review. Retrieved from https://hbr.org/2013/05/can-you-reallyimprove-your-em

Chesley, J., \& Wylson, A. (2016). Ambiguity: the emerging impact of mindfulness for change leaders. Journal of Change Management, 16(4), 317-336. doi:10.1080/14697017.2016.1230334

Clarke, D. (2015). Bloom's taxonomy of learning domains. Performance Juxtaposition. Retrieved from www.nwlink.com/ donclark/hrd/bloom.html

Duczyminski, P. (2017). Reaching students' affective domain of learning —Firefighter training. Fire Engineering, 170(4). Retrieved from http://www.fireengineering.com/articles/print/volume-170/issue-4.html

Ehrlich, J. (2015). Creating mindful leaders and organizations. People \& Strategy, 38(3), 22-25.

Ferres, N., \& Connell, J. (2004). Emotional intelligence in leaders: An antidote for cynicism towards change? Strategic Change, 13(2), 61-71. doi:10.1002/jsc.665

Fossas A. (2015). The basics of mindfulness: where did it come from? Welldoing.org. Retrieved from https://welldoing.org/article/basics-of-mindfulness-come-from

Frasson, C., \& Heraz, A. (2012). Emotional learning. In N. M. Seel (Ed.), Encyclopedia of the sciences of learning. Retrieved from http://www.iro.umontreal.ca/ frasson/FrassonPub/Encyclopedia-\%20Frasson-Heraz.pdf 
Frizzell, D. A., Hoon, S., \& Banner, D. K. (2016). A phenomenological investigation of leader development and mindfulness meditation. Journal of Social Change, 8(1), 14-25. doi:10.5590/JOSC.2016.08.1.02

Gebauer, A. (2013). Mindful organizing as a paradigm to develop managers. Journal of Management Education, 37(2), 203-228. doi:10.1177/1052562912458573

Goleman, D. (2004). What makes a leader? Harvard Business Review, 82(1), 82-91.

Gunter, H. (2001). Critical approaches to leadership in education. Journal of Educational Enquiry, 2(2), 94-108. Retrieved from http://www.ojs.unisa.edu.au/index.php/EDEQ/ article/view/583/455

Kocis, K. (2017, May 9). Why emotional intelligence is so hard [Web log post]. Retrieved from https://magazine.vunela.com/why-emotional-intelligence-is-so-hard-28494395a5da

Krathwohl, D. R., Bloom, B. S., \& Masia, B. B. (1964). Taxonomy of educational objectives: Handbook II: Affective domain. New York, NY: David McKay.

Kroon, B., van Woerkom, M., \& Menting, C. (2017). Mindfulness as substitute for transformational leadership. Journal of Managerial Psychology, 32(4), 284-297. doi:10.1108/JMP-07-2016-0223

Lyddy, C. J., Schachter, Y., Reyer, A., \& Julliard, K. (2016). Transfer of mindfulness training to the work setting: A qualitative study in a health care system. Journal of Continuing Education in the Health Professions, 36(4), 240-248. doi:10.1097/CEH.0000000000000120

Marchant, J. (2013, March 4). We make all our decisions based on feelings. Retrieved from http://www.emotionalintelligenceatwork.com/resources/we-make-all-our-decision-basedon-feelings/

McLeod, S. (2017) Kolb_Learning styles. Retrieved from https://www.simplypsychology.org/learning-kolb.html

Palmer, B. R., \& Gignac, G. (2012). The impact of emotionally intelligent leadership on talent retention, discretionary effort and employment brand. Industrial \& Commercial Training, 44(1), 9-18. doi:10.1108/00197851211193372

Pierre, E., \& Oughton, J. (2007). The affective domain: Undiscovered country. College Quarterly, 10(4), 1-7. Retrieved from https://eric.ed.gov/?id=EJ813766

Pullagurla, A. (2014, January 20). 6 top facts about adult learning theory [Web log post]. Retrieved from https://elearningindustry.com/6-top-facts-about-adult-learning-theoryevery-educator-should-know 
Selva, J. (2017, March 13). History of mindfulness: From east to west and from religion to science [Web log post]. Retrieved from https://positivepsychologyprogram.com/historyof-mindfulness/

Shields, C. (2010). Transformative leadership: Working for equity in diverse contexts. Educational Administration Quarterly, 4(4), 558-589. doi:10.1177/0013161X10375609

Simpson E. J. (1972). The classification of educational objectives in the psychomotor domain. Washington, DC: Gryphon House.

Szalavitz, M. (2012, January 11). Q\&A: Jon Kabat-Zinn talks about bringing mindfulness meditation to medicine. Time. Retrieved from http://healthland.time.com/2012/01/11/mind-reading-jon-kabat-zinn-talks-aboutbringing-mindfulness-meditation-to-medicine/

Training Industry. (2014, January 28). The 70:20:10 model for learning and development. Retrieved from https://trainingindustry.com/wiki/the-702010-model-for-learning-anddevelopment-cpdc/

Ugoani, J. N. N., Amu, C. U., \& Kalu, E. O. (2015). Dimensions of emotional intelligence and transformational leadership: A correlation analysis. Independent Journal of Management \& Production, 6(2), 563-584. doi:10.14807/ijmp.v6i2.278

Velisavljevic, L. (2015, February 24). What is emotional intelligence? Psychtastic. Retrieved from http://psychtastic.com/emotional-intelligence-salovey-mayer/

Vich, M. (2015). The emerging role of mindfulness research in the workplace and its challenges. Central European Business Review, 4(3), 35-47. doi:10.18267/j.cebr.131

Wight, A. R. (1971). Affective goals in education. Salt Lake City, UT: Interstate Education Resource Service Center. Retrieved from https://files.eric.ed.gov/fulltext/ED069733.pdf

Yanofsky, S. D., \& Nyquist, J. G. (2014). Using the affective domain to enhance teaching of the ACGME competencies in anesthesiology training. The Journal of Education in Perioperative Medicine, 12(1). Retrieved from https://www.ncbi.nlm.nih.gov/pmc/articles/PMC4719552/

\section{Author Biography}

Tarek M. Kaoun, M.Ed., CTP is a Learning and Development Professional specializing in organizational learning. He is passionate about helping his learners and the organizations that they serve to achieve and surpass their goals. His research interests are in emotional intelligence, mindfulness, leadership development, and organizational development. Kaoun.tarek@gmail.com 